\title{
Research on Human Resource and Strategic Innovation of Private Enterprises
}

\author{
Yanna Wei, a \\ ${ }^{1}$ Xi'an International University, Xi'an, Shaanxi, 710077 \\ a email
}

Keywords: Human Resource, Strategic Innovation, Private Enterprise

\begin{abstract}
With the deepening of the degree of economic marketization in China, the private economy will inevitably play a more active role in the national economy. However, there are many shortcomings in the human resources management of private enterprises in China, mainly in the lack of strategic thinking in human resources management, defects in the human resources system and in the actual operation of the non-standard. Therefore, private enterprises must build a high degree of strategic management of human resources management system, and continuously improve the level of human resources management of private enterprises, the only way to cultivate the core competitiveness of enterprises from the most essential elements.
\end{abstract}

\section{Introduction}

Since the beginning of the 20th century, the nature of human resource management has undergone tremendous changes, and the scope of management has been continuously expanding its requirements for functions and technologies as management changes are increasing. Faced with the increasing global competition and cost, efficiency, quality requirements, the effective management of human resources to ensure that the key to competitive advantage in the enterprise market. As a result, more and more human resources researchers have called for a combination of human resource management systems and organizational strategies from the 1980s to focus on synergies with many human resources initiatives to ensure consistency with the organization's overall needs. New century "non-coherent" competitive environment, making many companies gradually realize that to establish their own competitive advantage, the key is how to establish and run effective human resources management. In order to meet the challenge, the role of enterprise human resource managers has gradually changed from the past management, general affairs, welfare managers into enterprise learning, education promoters, senior executives, strategic business partners, management functions and change Of the advocates and so on. Human resource practitioners are increasingly involved in corporate strategy, business activities, leading enterprise change, building competitive advantage, disseminating functional skills and taking on the role of employee advocates and advocates, and are responsible for employee performance and productivity.

\section{The Development of Private Enterprises and Its Current Situation}

Chinese private enterprises in the role of economic development can not be ignored, in the national economic development of private enterprises to play a more and more strategic role. Since the mid-1990s, the private economy has maintained a sustained and rapid development momentum, the private economy has become an important part of the national economy, Chinese economic growth as the biggest source of power. According to the National Bureau of Statistics, by November 2006, the industrial added value of industrial enterprises above designated size was 1503 billion yuan, up 25 percent year on year, 8.2 percentage points higher than the national growth rate; the proportion of industrial added value above the national scale To 19.26\%, an increase of about 1.5 percentage points over 2005. At present, in addition to state-owned and state-owned economy outside the generalized private economy has accounted for about 65\% of GDP, of which individual and private economy has accounted for about $40 \%$; Chinese economic development in the incremental part of $70 \%$ to $80 \%$ from the private economy. 
It is a very important aspect of the whole society to change the economic situation of the backward areas and promote the relative balanced development of the region. Since the reform and opening up the history shows that the development of private economy is to change the regional economy is relatively backward a major factor. Since the mid-1980s, Jiangsu and Zhejiang since the mid-90s, since the mid-90s in Fujian and other places, are mainly rely on the development of private economy was able to quickly catch up and exceed the national level of growth. At present, the central and western regions have recognized that to speed up the transformation of economic backwardness, vigorously develop the private economy is a major way out. Since the mid-90s of the 20th century, the private economy is mostly labor-intensive industries, and the employment of flexible, and gradually become the absolute solution to solve the problem of social employment in China. According to the State Administration for Industry and Commerce statistics, as of the third quarter of 2007, employing 70,586,000 people, an increase of 9.8\%; the number of investors 1362.1 million, an increase of $7.1 \%$. At present, the non-public economy provides more than $75 \%$ of the urban jobs. Most of the laid-off workers in state-owned enterprises have realized re-employment in private enterprises. A large proportion of migrant workers in 120 million migrant workers are also working in private enterprises. Especially in recent years, private enterprises have begun to become graduates of Chinese colleges and universities Employment of one of the important channels.

\section{Selection and Formulation of Human Resources Strategy for Private Enterprises}

Enterprise strategy is a group of enterprise activity decision-making, private enterprise strategic objectives depends on a series of functional strategies, and this series of functional strategies in the most important human resources strategy. Levin Mitchell (1995) pointed out that the coordination of human resources strategy and corporate strategy can help enterprises to use market opportunities to enhance the internal organizational advantages of enterprises to help enterprises achieve strategic objectives. As a force to promote Chinese economic development, private enterprises in the accession to the WTO after the economic globalization and knowledge economy challenges, in the fierce competition in an invincible position, to improve the ability to participate in international competition, private enterprises must Develop a corporate strategy that fits its enterprise development and develop a human resource strategy that is appropriate to its corporate strategy. The following is based on several different private enterprise strategy to provide its matching human resources strategy. Rapid change makes strategy more important in business management than ever before, and makes making strategies more difficult. Because there are many issues to consider and limited time and resources, managers must focus and effectively articulate issues that are truly important to the business, including human resource issues. In this new environment, strategic management is more and more attention. However, the strategy has become more tentative, short-term and targeted. The value of an enterprise plan is more expressed as a tool for providing thinking and discussion rather than as a process of determining long-term goals and course of action.

Corporate strategy is used as a guide to help companies understand and clarify issues that need to be changed and give businesses the opportunity to manage these changes effectively. These strategies focus on the most important issues to make management open an "opportunity window" for action. The process of developing a strategic plan creates "breathtaking time" for managers to explore key issues. Private enterprises are recognizing that the emphasis on corporate finance and technology must be consistent with the importance of developing a human resource strategy. Some companies use human resources as part of the corporate strategic plan. Human resources strategy and financial, marketing, technology, manufacturing and information management functions like the strategy to support the entire business strategy. Some companies have a separate human resources strategy, which is usually aimed at the role and objectives of human resources functions. As long as the issues identified are relevant to the enterprise, these strategies can also effectively support the strategic focus of the enterprise. In today's rapidly changing environment, an important goal of implementing a human resource strategy is to lead a more flexible and more appropriate organization. In order to achieve the strategy of private enterprises, we need to implement a human 
resource strategy that focuses on people-related issues. The human resource strategy is not only a series of action plans related to human resource management, but also a whole, multi-faceted, long-term schedule that changes the original characteristics of an enterprise. Logically, the HR strategy is part of the overall corporate strategy, but in practice, corporate strategy and human resource strategy are often developed separately. In any way, these two strategies are used to translate human resource issues into action plans; they use human resources management as the foundation for implementing corporate strategy, combining human management with business management. For the private enterprises, in the establishment and improvement of modern enterprise system, based on the establishment of modern human resources management concept, from the perspective of resources to re-examine the value of employees, the use of new human resources strategy management theory and management methods to achieve the traditional personnel management To the transformation of modern human resources strategic management.

\section{Implementation of Human Resources Strategy in Private Enterprises}

In the process of concrete implementation of human resources strategy, due to the limited human reasoning, the internal and external environment of the chaotic changes, are likely to make the initial development of human resources strategy can not really achieve the enterprise to achieve the desired goal and requirements, therefore, The establishment of a scientific evaluation and control system, the use of evaluation results on the initial human resources strategy to adjust to adapt to the changes in the internal and external environment, to amend the implementation of human resources strategy in the deviation, and ultimately to ensure the continued realization of human resources strategy. Therefore, the systematic feedback of human resources strategy, evaluation and control has become an important work on the interests of private enterprises. The basic purpose of human resource strategy and evaluation and control is to ensure that the human resources strategy originally developed by private enterprises and their specific implementation process are adapted to each other in real time. The basic contents of the evaluation and control of human resources strategy include: selecting the key monitoring and evaluation points in the key link of human resource strategy, establishing the evaluation and control benchmarks and principles, monitoring and evaluating the actual changes and changing trends of key control points, selecting appropriate Control and correct control methods, adjust the deviation. The tools for the evaluation and control of human resource strategies generally include: human resources management information systems, budgetary algorithms, quantitative analysis, and so on.

Focusing on the results of the evaluation, rather than the activities and daily operational efficiency, so that we can focus on the initial identified important issues. In the 1990s, a human resource strategy was needed to focus on the solution to the final outcome problem, not just the means. However, the measurement of the outcome of the problem requires a more detailed and comprehensive process of identifying the problem, and requires the development of a management action plan. Therefore, the strategic approach to human resources is becoming a more demanding task for managers.

Each of the books and each model of the strategic plan includes a section titled "Evaluation and Control". It is the last word used in strategy formulation and implementation. It is an important aspect, because too many private enterprises in the development and implementation of the plan in the process of never evaluation, not sure whether to clarify the appropriate issues, whether to take the appropriate strategy, whether the resources are properly used, expected Whether the result is reached. However, as time goes on, action is also underway; managers' attention is placed on the next wave of activity and investment, with little interest or patience to evaluate the process. Moreover, there are few means of performing performance measurement and auditing.

\section{Conclusion}

Private enterprises in order to meet the challenges of the future, we must develop a human resources strategy, and strategic management. The future of private enterprises if you want to achieve greater 
development must actively learn from and learn from foreign human resources management of new ideas, new knowledge, new technology, while the spirit of scientific research to explore how these latest knowledge and technology with China The combination of the actual situation, so that enterprises through the improvement of human resources management to seek competitive advantage. But we also need to recognize such a problem, human resources, strategic management itself is a combination of science and art, only the concept of human resources strategy management and technology is far from enough, all levels of business managers, especially the top managers for The understanding of human resources strategy management and the management art of mastery are very important for the improvement of the overall human resource management level. Private enterprises in order to continue to be successful, we need to human resources, strategic management and long-term development of enterprises combined, step by step implementation.

\section{References}

[1] Hu Xiaoling. Role Customization of Organizational Citizenship Behavior [J]. China Human Resource Development, 2006 (09)

[2] Ge Peibo. An Effective Way to Cultivate Organizational Citizenship Behavior [J]. China Human Resources Development, 2006 (09)

[3] Pan Jinyun, Chen Xiaoping. Human capital is the basic wealth of workers [J]. China Human Resources Development, 2006 (07)

[4] Zeng Liping. The opponents [J]. Manager, 2005 (09)

[5] Chen Qunping. Chinese private enterprise human resource management strategy research [J]. Economist, 2005 (05) 